\title{
USO DE ETIL-TRINEXAPAC EM CULTIVARES DE ARROZ DE TERRAS ALTAS ${ }^{1}$
}

\author{
Orivaldo Arf ${ }^{2}$, Vagner do Nascimento ${ }^{2}$, Ricardo Antônio Ferreira Rodrigues ${ }^{2}$, \\ Rita de Cássia Félix Alvarez ${ }^{3}$, Douglas de Castilho Gitti ${ }^{2}$, Marco Eustáquio de Sá ${ }^{2}$
}

\begin{abstract}
USE OF ETHYL-TRINEXAPAC

IN UPLAND RICE CULTIVARS

The lodging of some rice cultivars, at harvest time, can cause significant losses in grain yield. The use of plant regulators is one of the alternatives to reduce lodging, however, information on that subject are still scarce. This study aimed to evaluate the use of ethyl-trinexapac doses $\left(0 \mathrm{~g} \mathrm{ha}^{-1}, 50 \mathrm{~g} \mathrm{ha}^{-1}, 100 \mathrm{~g} \mathrm{ha}^{-1}\right.$, $150 \mathrm{~g} \mathrm{ha}^{-1}$, and $200 \mathrm{~g} \mathrm{ha}^{-1}$ ), at the floral differentiation stage, in rice cultivars with different types of plants (Caiapó - traditional; BRS Primavera and BRS Soberana - intermediate; and IAC 202 modern), in order to evaluate grain development and yield. The experiment was carried out in Selvíria, Mato Grosso do Sul State, Brazil, during the 2007/2008 growing season. It was observed that the application of $50 \mathrm{~g} \mathrm{ha}^{-1}, 100 \mathrm{~g} \mathrm{ha}^{-1}$, and $150 \mathrm{~g} \mathrm{ha}^{-1}$ of ethyl-trinexapac, during the floral differentiation stage of the Caiapó, BRS Soberana, and BRS Primavera cultivars, respectively, decreased plants height and eliminated lodging; it was not necessary to use growth regulator for the IAC 202 cultivar, due to its lack of lodging; the application of $50 \mathrm{~g} \mathrm{ha}^{-1}$ and $150 \mathrm{~g} \mathrm{ha}^{-1}$ of ethyl-trinexapac, during the floral differentiation stage, improved grain yield for the Caiapó and BRS Primavera cultivars, respectively, and the $100 \mathrm{~g} \mathrm{ha}^{-1}$ dose interfered little in the BRS Soberana cultivar.
\end{abstract}

KEY-WORDS: Oryza sativa L.; plant lodging; plant growth regulators.

\section{INTRODUÇÃO}

O arroz constitui fonte importante de calorias e proteínas, na dieta alimentar do povo brasileiro. Entretanto, a produção deste cereal tem oscilado de ano para ano e, eventualmente, não tem sido suficiente para atender ao consumo interno do País, resultando na necessidade de importação do produto, a fim de proporcionar a manutenção dos estoques nacionais (Conab 2012).

\section{RESUMO}

O acamamento de plantas em cultivares de arroz, no momento da colheita, acarreta perdas significativas à produtividade. O uso de reguladores vegetais é uma das alternativas para reduzir o acamamento, entretanto, as informações sobre este assunto ainda são escassas. Este trabalho foi desenvolvido com o objetivo de avaliar o uso de doses de etiltrinexapac $\left(0 \mathrm{~g} \mathrm{ha}^{-1}, 50 \mathrm{~g} \mathrm{ha}^{-1}, 100 \mathrm{~g} \mathrm{ha}^{-1}, 150 \mathrm{~g} \mathrm{ha}^{-1} \mathrm{e} 200 \mathrm{~g} \mathrm{ha}^{-1} \mathrm{do}\right.$ i.a.), aplicadas por ocasião da diferenciação floral, em cultivares de arroz com diferentes tipos de plantas (Caiapó - tradicional; BRS Primavera e BRS Soberana - intermediário; e IAC 202 moderno), avaliando o desenvolvimento e a produtividade de grãos. O experimento foi desenvolvido no município de Selvíria (MS), durante o ano agrícola de 2007/2008. Concluiu-se que a aplicação de $50 \mathrm{~g} \mathrm{ha}^{-1}, 100 \mathrm{~g} \mathrm{ha}^{-1} \mathrm{e} 150 \mathrm{~g} \mathrm{ha}^{-1}$ de etil-trinexapac, por ocasião da diferenciação do primórdio da panícula das cultivares Caiapó, BRS Soberana e BRS Primavera, respectivamente, reduziu a altura de plantas e proporcionou ausência de acamamento; a cultivar IAC 202 dispensou o uso de regulador de crescimento, considerando-se que a mesma praticamente não apresentou acamamento; a aplicação de $50 \mathrm{~g} \mathrm{ha}^{-1}$ e $150 \mathrm{~g} \mathrm{ha}^{-1}$ de etil-trinexapac, por ocasião da diferenciação do primórdio da panícula, melhorou a produtividade da cultivar Caiapó e BRS Primavera, respectivamente, e a dose de $100 \mathrm{~g} \mathrm{ha}^{-1}$ interferiu pouco na cultivar BRS Soberana.

PALAVRAS-CHAVE: Oryza sativa L.; acamamento de plantas; reguladores vegetais.

Uma das alternativas para atender ao consumo interno é o aumento da produtividade da cultura, o que pode ser alcançado com a utilização da irrigação por aspersão. O sistema irrigado por aspersão é uma alternativa para solucionar o problema de verani$\cos$, conferindo estabilidade à produção, podendo, também, aumentar a produtividade e melhorar a qualidade de grãos (Arf et al. 2000).

Nas regiões Centro-Oeste, Norte e Nordeste, a área cultivada com arroz de terras altas vem

1. Trabalho recebido em mar./2011 e aceito para publicação em abr./2012 ( ${ }^{\circ}$ registro: PAT 13711).

2. Universidade Estadual Paulista “Júlio de Mesquita Filho", Faculdade de Engenharia, Ilha Solteira, SP, Brasil.

E-mails: arf@agr.feis.unesp.br, vagnern@gmail.com, ricardo@agr.feis.unesp.br, gittidouglas@hotmail.com, mesa@agr.feis.unesp.br. 3. Universidade Federal do Mato Grosso, Setor de Fitotecnia, Chapadão do Sul, MS, Brasil.E-mail: ritaalvarez@nin.ufms.br. 
diminuindo anualmente, e os motivos são a concorrência com a soja e o milho e a diminuição da abertura de áreas novas de lavoura, onde o arroz tem preferência no primeiro ano de cultivo, apresentado baixas produtividades nos anos subsequentes (Conab 2011).

O arroz de terras altas cultivado com o uso da irrigação por aspersão pode proporcionar estabilidade de produção e lucratividade, estimulando o uso de práticas de maior nível tecnológico, com consequente aumento na produtividade. No entanto, estas práticas podem estimular o desenvolvimento exagerado das plantas de algumas cultivares, ocasionando acamamento, o que dificulta a colheita mecanizada.

Diversos estudos têm evidenciado a viabilidade do uso de reguladores vegetais na redução do crescimento vegetativo e do consequente acamamento em trigo (Zagonel \& Fernandes 2007, Espindula et al. 2010), arroz (Alvarez et al. 2007, Nascimento et al. 2009, Gitti et al. 2011), crotalária (Kappes et al. 2011) e girassol (Mateus et al. 2009).

Os reguladores de crescimento vegetal podem ser usados com relativa flexibilidade pelo agricultor, para ajustar sua cultura ao objetivo desejado, alterando as condições de crescimento. Na Europa, estes produtos são utilizados para pequenos cultivos de grãos, onde se tornaram parte integrante do sistema de produção, reduzindo riscos de acamamento pela redução do crescimento vegetativo excessivo (Rademacher 2000).

Dentre os diversos reguladores vegetais, os inibidores da síntese de ácido giberélico, como o etil-trinexepac, são os de maior potencial para utilização na cultura do arroz de terras altas, com reduções significativas do desenvolvimento vegetativo das plantas, entretanto, têm acarretado decréscimos na produtividade. Alvarez et al. (2007), estudando o efeito do etil-trinexapac, em casa-de-vegetação, na redução da altura da planta de arroz irrigado por aspersão, aplicado na diferenciação do primórdio da panícula, na dose de $200 \mathrm{~g} \mathrm{ha}^{-1}$ do i.a., verificaram que o regulador vegetal reduziu a altura de plantas em $0,34 \mathrm{~m}$ e influenciou negativamente os componentes da produção e a produtividade de grãos. Já Nascimento et al. (2009), em avaliações a campo, obtiveram resposta positiva da aplicação do regulador de crescimento etil-trinexapac sobre a produtividade de grãos, na dose de $150 \mathrm{~g} \mathrm{ha}^{-1}$ do i.a., aplicado na diferenciação floral da cultivar de arroz Primavera, com eliminação do acamamento.
Assim, a adoção de técnicas de cultivo que possibilitem melhorar o manejo da cultura do arroz, em condições favoráveis ao desenvolvimento das plantas, pode ser de suma importância para o aumento da produtividade e qualidade dos grãos.

Visando a reduzir a altura de plantas e, consequentemente, o acamamento, desenvolveu-se este estudo, com o objetivo de avaliar o efeito de doses de etil-trinexapac, aplicadas por ocasião da diferenciação floral, no desenvolvimento e produtividade de grãos de cultivares de arroz, com diferentes tipos de plantas.

\section{MATERIAL E MÉTODOS}

O trabalho foi conduzido em área experimental pertencente à Faculdade de Engenharia da Universidade Estadual Paulista, Campus de Ilha Solteira, localizada no município de Selvíria (MS) (20²2’S, $51^{\circ} 22^{\prime} \mathrm{W}$ e altitude de $335 \mathrm{~m}$ ). O solo do local é do tipo Latossolo Vermelho distrófico argiloso (Embrapa 1999). A precipitação média anual é de $1.370 \mathrm{~mm}$, a temperatura média anual de $23,5^{\circ} \mathrm{C}$ e a umidade relativa do ar de $70 \%$ a $80 \%$ (média anual).

Antes da instalação do experimento, foi coletada amostra composta, originada de 20 amostras simples do solo da área experimental, na camada 0-0,20 m. A análise da fertilidade do solo, segundo método descrito por Raij \& Quaggio (1983), apresentou os seguintes valores: M.O. $=13 \mathrm{~g} \mathrm{dm}^{-3}$; P resina $=$ $28 \mathrm{mg} \mathrm{dm}^{-3} ; \mathrm{pH}(\mathrm{CaCl} 2)=4,9 ; \mathrm{K}^{+}=0,31 \mathrm{cmol}_{\mathrm{c}} \mathrm{dm}^{-3}$; $\mathrm{Ca}^{+2}=1,6 \mathrm{cmol}_{\mathrm{c}} \mathrm{dm}^{-3} ; \mathrm{Mg}^{+2}=0,4 \mathrm{cmol}_{\mathrm{c}} \mathrm{dm}^{-3} ; \mathrm{H}+\mathrm{Al}=$ $2,0 \mathrm{cmol}_{\mathrm{c}} \mathrm{dm}^{-3} ; \mathrm{e} \mathrm{V}=54 \%$.

$\mathrm{O}$ fornecimento de água foi realizado por sistema fixo de irrigação por aspersão, com precipitação média de 3,3 mm hora ${ }^{-1}$ nos aspersores. A precipitação pluvial foi determinada em um pluviômetro Ville de Paris, instalado a, aproximadamente, $500 \mathrm{~m}$ da área experimental.

Adotou-se o delineamento experimental em blocos ao acaso, disposto em esquema fatorial $5 \times 4$, com quatro repetições. Os tratamentos foram constituídos pela combinação de cinco doses do ingrediente ativo etil-trinexapac $\left(0 \mathrm{~g} \mathrm{ha}^{-1}, 50 \mathrm{~g} \mathrm{ha}^{-1}, 100 \mathrm{~g} \mathrm{ha}^{-1}\right.$, $150 \mathrm{~g} \mathrm{ha}^{-1}$ e $200 \mathrm{~g} \mathrm{ha}^{-1}$ ) e quatro cultivares (BRS Primavera, Caiapó, BRS Soberana e IAC 202). As parcelas foram constituídas por seis linhas de $5,0 \mathrm{~m}$ de comprimento, espaçadas em $0,35 \mathrm{~m}$ entre si, e a área útil pelas quatro linhas centrais, desprezando-se $0,50 \mathrm{~m}$ em ambas as extremidades de cada linha. A 
adubação nitrogenada em cobertura, utilizando-se como fonte o sulfato de amônio, foi aplicada aos 30 dias após a emergência das plantas, na dose de $60 \mathrm{~kg} \mathrm{ha}^{-1}$ de nitrogênio. Logo após a aplicação, foi realizada irrigação com, aproximadamente, $10 \mathrm{~mm}$ de água.

O regulador vegetal etil-trinexapac foi aplicado na época da diferenciação floral do arroz, na forma de jato dirigido, com pulverizador costal manual e volume de calda aproximado de $450 \mathrm{~L} \mathrm{ha}^{-1}$. As aplicações foram realizadas no período da manhã, entre $8 \mathrm{~h}$ e $9 \mathrm{~h}$, com umidade relativa próxima a $90 \%$ e ausência ou pouca incidência de vento (velocidade do vento entre $0 \mathrm{~m} \mathrm{~s}^{-1}$ e $1,0 \mathrm{~m} \mathrm{~s}^{-1}$ ), utilizando-se um anteparo de lona para evitar deriva a outras parcelas.

As cultivares avaliadas foram: 1) BRS Primavera: cultivar do tipo tradicional, proveniente do Centro Nacional de Pesquisa de Arroz e Feijão Embrapa, com porte médio (1,00-1,20 m), ciclo curto (112 dias), 80 dias da emergência ao florescimento, grãos tipo longo e fino (agulhinha), moderadamente susceptível à brusone (Pyricularia oryzaea Cav.) e ao acamamento (Breseghello et al. 1998); 2) Caiapó: cultivar do tipo tradicional, proveniente do Centro Nacional de Pesquisa de Arroz e Feijão - Embrapa, com porte médio $(1,10-1,30 \mathrm{~m})$, ciclo médio (128 dias), 95-100 dias da emergência ao florescimento, grãos tipo longo, moderadamente susceptível à brusone (Pyricularia oryzaea Cav.) e ao acamamento (Soares et al. 1993); 3) IAC 202: cultivar do tipo moderno, proveniente do cruzamento da cultivar Lemont com a IAC 25 , com porte baixo e intermediário $(0,87 \mathrm{~m})$, ciclo curto (88-110 dias), 68-93 dias da emergência ao florescimento, grãos tipo longo e fino (agulhinha), resistente à brusone (Pyricularia oryzaea Cav.) e ao acamamento (Bastos 2000); 4) BRS Soberana: cultivar do tipo tradicional, proveniente do Centro Nacional de Pesquisa de Arroz e Feijão - Embrapa, com porte médio (1,05-1,15 m), ciclo curto (105 dias), grãos tipo longo e fino (agulhinha), sensível ao acamamento, porém, em níveis inferiores aos observados em cultivares como a Primavera (Embrapa 2006).

O preparo do solo da área foi realizado utilizando-se escarificador e duas gradagens, sendo a última às vésperas da semeadura. A semeadura foi realizada no dia 07/11/2007, utilizando-se sementes necessárias para se obter 180 plantas $\mathrm{m}^{-2}$, em cada cultivar. Conjuntamente com a semeadura, foi reali- zada a aplicação de 1,5 $\mathrm{kg} \mathrm{ha}^{-1}$ de caborfuran (i.a.), visando ao controle de cupins e da lagarta elasmo.

A adubação química básica, nos sulcos de semeadura, foi realizada com a aplicação de $180 \mathrm{~kg} \mathrm{ha}^{-1}$ da formulação 08-28-16 $+\mathrm{Zn}+\mathrm{Ca}+\mathrm{S}$, calculada de acordo com as características químicas do solo e levando-se em consideração as recomendações de Cantarella \& Furlani (1996).

No manejo de água, foram utilizados até três coeficientes de cultura $(\mathrm{Kc})$, distribuídos em quatro períodos, compreendidos entre a emergência e a colheita. Para a fase vegetativa, foi utilizado o valor 0,4 ; para a fase reprodutiva, dois coeficientes de cultura (Kc): o inicial, de 0,70, e o final, de 1,00; e, para a fase de maturação, estes valores foram invertidos, ou seja, o inicial foi de 1,00 e o final de 0,70 .

O controle de plantas daninhas foi realizado com a utilização de herbicidas de pré e pós-emergência. Como na área de cultivo havia sido observada, com frequência, a presença de capim colchão (Digitaria sanguinalis), capim carrapicho (Cenchrus echinatus) e capim marmelada (Brachiaria plantaginea), foi aplicado, logo após a semeadura, o herbicida pendimethalin $\left(1.400 \mathrm{~g} \mathrm{ha}^{-1}\right.$ do i.a.). Aos 12 dias após a emergência das plantas, foi utilizado, em pós-emergência, o herbicida metsulfuron methyl ( $2 \mathrm{~g} \mathrm{ha}^{-1}$ do i.a.). As demais plantas daninhas não controladas pelos herbicidas foram eliminadas manualmente, com o auxílio de enxada.

Durante o período de condução do experimento, foram realizadas as seguintes avaliações: altura de plantas - média das distâncias da superfície do solo até a extremidade superior da panícula mais alta, determinada em dez plantas ao acaso; acamamento de plantas - obtido por observações visuais, na fase de maturação, utilizando-se a seguinte escala de notas: $0=$ sem acamamento; $1=$ até $5 \%$ de plantas acamadas; $2=5 \%$ a $25 \% ; 3=25 \%$ a $50 \% ; 4=50 \%$ a $75 \%$; e $5=75 \%$ a $100 \%$; número de colmos e de panículas por metro quadrado - contagem de colmos ou panículas em 1,0 $\mathrm{m}$ de fileira de plantas, posteriormente convertidos em colmos ou panículas por metro quadrado; perfilhamento útil - relação entre o número de panículas e colmos por metro quadrado; número total de grãos por panícula - contagem dos grãos de 20 panículas, coletadas no momento da colheita; número de grãos cheios e chochos por panícula contagem de grãos cheios e chochos, após a separação dos mesmos por fluxo de ar, obtidos com as amostras utilizadas para a determinação do número total de 
grãos; massa de cem grãos - massa de duas amostras de cem grãos; massa hectolitrica - determinada em balança especial para massa hectolítrica, utilizando-se duas amostras; produtividade de grãos - massa dos grãos provenientes da área útil, convertida em $\mathrm{kg} \mathrm{ha}^{-1}$. Os valores das massas foram corrigidos para umidade de $13 \%$ (base úmida).

Os dados foram submetidos a análise de variância e, posteriormente, à análise de regressão polinomial, para o fator quantitativo (doses do regulador de crescimento), e teste Tukey, para o fator qualitativo (cultivares de arroz).

\section{RESULTADOS E DISCUSSÃO}

Os dados referentes à altura e acamamento de plantas apresentaram interações significativas entre as cultivares e doses do regulador de crescimento. $\mathrm{Na}$ avaliação de cultivares, dentro de doses, diferenças foram observadas entre as cultivares, onde, de maneira geral, a BRS Soberana e Caiapó se destacaram com plantas mais altas, em relação às demais, sendo IAC 202 a cultivar de menor altura (Tabela 1).

Quanto às doses do regulador de crescimento, as quatro cultivares apresentaram ajuste da altura de plantas a funções lineares decrescentes, ou seja, o uso do regulador de crescimento propiciou redução significativa na altura de planta. O etil-trinexapac não inibe totalmente o desenvolvimento da planta, mas regula seu desenvolvimento, pela inibição da enzima $3 \beta$-hidroxila, responsável pela síntese da giberelina $\mathrm{GA}_{1}$, mais ativa biologicamente na planta (Heckman et al. 2002). Desta forma, existe um crescimento mais lento, pela ação de giberelinas menos eficientes no processo de alongação celular.

Nascimento et al. (2009), considerando a redução na altura de plantas e eliminação do acamamento, recomendam a aplicação de $150 \mathrm{~g} \mathrm{ha}^{-1} \mathrm{de}$ etil-trinexapac, por ocasião da diferenciação floral da cultivar BRS Primavera. Em relação ao presente trabalho, a dose de $150 \mathrm{~g} \mathrm{ha}^{-1}$ de etil-trinexapac, também aplicada na diferenciação floral, para as cultivares BRS Primavera e BRS Soberana, apresentou $1,16 \mathrm{~m}$ de altura de planta, sendo $0,20 \mathrm{~m}$ e $0,37 \mathrm{~m}$, respectivamente, menores, em relação ao tratamento testemunha sem regulador. Já as cultivares IAC 202 e Caiapó apresentaram, nesta dose, altura de plantas inferior a 1,00 m e, no caso da Caiapó, a redução de altura de planta, em relação ao tratamento testemunha, atingiu $0,51 \mathrm{~m}$.

A redução na altura das plantas de arroz é maior a partir de aplicações na diferenciação floral, uma vez que o tamanho das plantas de arroz é determinado pelo alongamento dos últimos quatro entrenós e inicia-se com a iniciação do primórdio da panícula, sendo que o alongamento do último entrenó determina a emergência da panícula através da bainha da "folha bandeira" (Fornasieri Filho \& Fornasieri

Tabela 1. Altura e acamamento de plantas, em função de doses de etil-trinexapac e cultivares de arroz de terras altas irrigadas por aspersão (Selvíria, MS, 2007/2008).

\begin{tabular}{|c|c|c|c|c|c|c|}
\hline \multirow{4}{*}{ Cultivares } & \multicolumn{5}{|c|}{ Doses de etil-trinexapac $\left(\mathrm{g} \mathrm{ha}^{-1}\right)$} & \multirow{4}{*}{$\begin{array}{l}\text { Ajuste de } \\
\text { regressão }\end{array}$} \\
\hline & 0 & 50 & 100 & 150 & 200 & \\
\hline & \multicolumn{5}{|c|}{ Altura de plantas } & \\
\hline & \multicolumn{5}{|c|}{$\mathrm{m}-$} & \\
\hline BRS Primavera & $1,36 \mathrm{~b}$ & $1,33 \mathrm{~b}$ & $1,22 \mathrm{~b}$ & $1,16 \mathrm{a}$ & $1,04 \mathrm{~b}$ & $\mathrm{RL}^{*}(1)$ \\
\hline BRS Soberana & $1,53 \mathrm{a}$ & $1,43 \mathrm{a}$ & $1,32 \mathrm{a}$ & $1,16 \mathrm{a}$ & $1,15 \mathrm{a}$ & $\mathrm{RL}^{*}(2)$ \\
\hline IAC 202 & $1,16 \mathrm{c}$ & $1,08 \mathrm{c}$ & $0,97 \mathrm{c}$ & $0,94 \mathrm{~b}$ & $0,88 \mathrm{c}$ & $\mathrm{RL}^{*}(3)$ \\
\hline Caiapó & $1,50 \mathrm{a}$ & $1,35 \mathrm{ab}$ & $1,21 \mathrm{~b}$ & $0,99 \mathrm{~b}$ & $0,87 \mathrm{c}$ & $\mathrm{RL}^{*}(4)$ \\
\hline \multicolumn{7}{|c|}{$\mathrm{DMS}=0,0807 ; \mathrm{CV}=3,66 \%$} \\
\hline \multirow{2}{*}{ Cultivares } & \multicolumn{5}{|c|}{ Acamamento $^{\mathrm{a}}$} & \\
\hline & & & - Notas $^{\mathrm{a}}$ & & & \\
\hline BRS Primavera & $5,0 \mathrm{a}$ & $3,0 \mathrm{a}$ & $0,8 \mathrm{a}$ & 0,0 & 0,0 & $\mathrm{RL}^{*}(5)$ \\
\hline BRS Soberana & $3,8 \mathrm{~b}$ & $0,3 \mathrm{~b}$ & $0,0 \mathrm{a}$ & 0,0 & 0,0 & $\mathrm{~ns}$ \\
\hline IAC 202 & $0,0 \mathrm{c}$ & $0,0 \mathrm{~b}$ & $0,0 \mathrm{a}$ & 0,0 & 0,0 & ns \\
\hline Caiapó & $4,5 \mathrm{ab}$ & $0,0 \mathrm{~b}$ & $0,0 \mathrm{a}$ & 0,0 & 0,0 & ns \\
\hline \multicolumn{7}{|c|}{$\mathrm{DMS}=0,9281 ; \mathrm{CV}=16,71 \%$} \\
\hline
\end{tabular}


2006). Cuidados devem ser tomados em aplicações tardias, pois podem reduzir o comprimento do último entrenó e reter parte ou toda a panícula na bainha da folha bandeira, interferindo na antese e na formação dos grãos, como observado por Zagonel \& Fernandes (2007), em cultivares de trigo.

Quanto ao acamamento de plantas, as cultivares BRS Primavera, BRS Soberana e Caiapó não apresentaram acamamento a partir das doses de $150 \mathrm{~g} \mathrm{ha}^{-1}, 100 \mathrm{~g} \mathrm{ha}^{-1}$ e $50 \mathrm{~g} \mathrm{ha}^{-1}$ de etil-trinexapac, respectivamente (Tabela 1). Na dose de $150 \mathrm{~g} \mathrm{ha}^{-1}$ de etil-trinexapac, não foi registrado acamamento de plantas, para as cultivares avaliadas. A cultivar IAC 202 não apresentou acamamento de plantas, mesmo no tratamento sem regulador de crescimento. O regulador de crescimento pode beneficiar a arquitetura de planta, de forma que as folhas fiquem mais eretas, reduzindo o sombreamento e aumentando a interceptação solar e, consequentemente, a taxa fotossintética.

A redução no desenvolvimento da planta em altura diminui o risco de acamamento, tornando a planta mais compacta e possibilitando melhor aproveitamento dos fotoassimilados, uma vez que $60 \%$ dos fotoassimilados são utilizados na alongação dos entrenós superiores e o restante é direcionado ao crescimento das folhas e panículas jovens (Murata \& Matsushima 1978).

$\mathrm{O}$ aumento das doses de etil-trinexapac incrementou o número de colmos $\mathrm{m}^{-2}$ da IAC $202 \mathrm{em}$ doses menores do regulador de crescimento que das cultivares BRS Primavera, BRS Soberana e Caiapó, sendo estimada em $55 \mathrm{~g} \mathrm{ha}^{-1}$ do etil-trinexapac, segundo ajuste dos dados a uma equação quadrática (Tabela 2). Como a cultivar IAC 202 apresenta menor altura de plantas, doses inferiores foram necessárias para reduzir ainda mais seu comprimento, e, provavelmente, proporcionou condições favoráveis ao desenvolvimento dos perfilhos, devido à maior radiação solar. A emissão de perfilhos pode ser controlada pela concentração de auxina no colmo principal.

O sombreamento das folhas inferiores causa aumento da dominância apical, reduzindo o desenvolvimento das gemas laterais ou perfilhos (Fornasieri Filho \& Fornasieri 2006). Este fato também foi observado nas demais cultivares avaliadas, porém, em doses superiores a $100 \mathrm{~g} \mathrm{ha}^{-1}$ do etil-trinexapac. Talvez, a maior altura das cultivares BRS Primavera, BRS Soberana e Caiapó, em relação à IAC 202, justifique as maiores doses do regulador de crescimento necessárias para aumentar o número de colmos $\mathrm{m}^{-2}$.

Tabela 2. Número de colmos e panículas $\mathrm{m}^{-2}$ e perfilhamento útil, em função de doses de etil-trinexapac e cultivares de arroz de terras altas irrigadas por aspersão (Selvíria, MS, 2007/2008).

\begin{tabular}{|c|c|c|c|c|c|c|}
\hline \multirow{2}{*}{ Cultivares } & \multicolumn{5}{|c|}{ Doses de etil-trinexapac $\left(\mathrm{g} \mathrm{ha}^{-1}\right)$} & \multirow{2}{*}{$\begin{array}{l}\text { Ajuste de } \\
\text { regressão }\end{array}$} \\
\hline & 0 & 50 & 100 & 150 & 200 & \\
\hline \multicolumn{7}{|c|}{ Número de colmos $m^{-2}$} \\
\hline BRS Primavera & $261,7 \mathrm{~b}$ & $258,0 \mathrm{~b}$ & $288,8 \mathrm{~b}$ & $333,8 \mathrm{a}$ & $310,5 \mathrm{~b}$ & $\mathrm{RL}^{*}(1)$ \\
\hline BRS Soberana & $325,0 \mathrm{a}$ & $278,0 \mathrm{~b}$ & $287,0 \mathrm{~b}$ & $261,0 \mathrm{~b}$ & $329,3 \mathrm{ab}$ & $\mathrm{RQ} *(2)$ \\
\hline IAC 202 & $282,0 \mathrm{ab}$ & $367,0 \mathrm{a}$ & $399,0 \mathrm{a}$ & $362,0 \mathrm{a}$ & $288,0 \mathrm{~b}$ & $\mathrm{RQ} *(3)$ \\
\hline Caiapó & $293,0 \mathrm{ab}$ & $272,0 \mathrm{~b}$ & $278,0 \mathrm{~b}$ & $334,0 \mathrm{a}$ & $379,0 \mathrm{a}$ & $\mathrm{RQ} *(4)$ \\
\hline \multicolumn{7}{|c|}{$\mathrm{DMS}=51,9277 ; \mathrm{CV}=8,97 \%$} \\
\hline \multicolumn{7}{|c|}{ Número de panículas $m^{-2}$} \\
\hline BRS Primavera & $221,3 \mathrm{~b}$ & $210,0 \mathrm{a}$ & $248,3 \mathrm{~b}$ & $254,3 \mathrm{a}$ & $223,5 \mathrm{ab}$ & $\mathrm{ns}$ \\
\hline BRS Soberana & $276,0 \mathrm{a}$ & $237,0 \mathrm{a}$ & $268,0 \mathrm{a}$ & $206,0 \mathrm{a}$ & $261,5 \mathrm{a}$ & $\mathrm{ns}$ \\
\hline IAC 202 & $230,0 \mathrm{ab}$ & $225,0 \mathrm{a}$ & $239,0 \mathrm{ab}$ & $233,0 \mathrm{a}$ & $181,8 \mathrm{~b}$ & $\mathrm{RQ} *(5)$ \\
\hline Caiapó & $230,0 \mathrm{ab}$ & $206,0 \mathrm{a}$ & $198,0 \mathrm{~b}$ & $240,0 \mathrm{a}$ & $191,0 \mathrm{~b}$ & ns \\
\hline \multicolumn{7}{|c|}{$\mathrm{DMS}=50,1751 ; \mathrm{CV}=6,89 \%$} \\
\hline \multicolumn{7}{|c|}{ Perfilhamento útil (\%) } \\
\hline BRS Primavera & $84,5 \mathrm{a}$ & $82,0 \mathrm{a}$ & $86,4 \mathrm{a}$ & $76,3 \mathrm{ab}$ & $71,8 \mathrm{ab}$ & $\mathrm{RL}^{*(6)}$ \\
\hline BRS Soberana & $85,1 \mathrm{a}$ & $85,5 \mathrm{a}$ & $93,4 \mathrm{a}$ & 78,9 a & 79,4 a & ns \\
\hline IAC 202 & $81,7 \mathrm{a}$ & $61,6 \mathrm{~b}$ & $59,9 \mathrm{~b}$ & $64,1 \mathrm{~b}$ & $63,3 \mathrm{bc}$ & $\mathrm{RQ} *(7)$ \\
\hline Caiapó & $78,9 \mathrm{a}$ & $76,0 \mathrm{a}$ & $71,5 \mathrm{~b}$ & $73,0 \mathrm{ab}$ & $50,8 \mathrm{c}$ & $\mathrm{RQ}^{*(8)}$ \\
\hline
\end{tabular}

Médias seguidas de mesma letra minúscula, nas colunas, não diferem estatisticamente entre si, pelo teste Tukey, a 5\%. * Significativo a $5 \%$, pelo teste F. ns = não significativo. ${ }^{(1)} \mathrm{y}=255,9000+0,3465\left(\mathrm{R}^{2}=0,72\right) ;{ }^{(2)} \mathrm{y}=325,6786-1,1341+0,0056 \mathrm{x}^{2}\left(\mathrm{R}^{2}=0,76\right) ;{ }^{(3)} \mathrm{y}=282,9143+2,2254 \mathrm{x}+0,0052 \mathrm{x}^{2}\left(\mathrm{R}^{2}=0,97\right) ;(4) \mathrm{y}=290,4000-0,5720 \mathrm{x}+$ $0,0052 \mathrm{x}^{2}\left(\mathrm{R}^{2}=0,97\right) ;{ }^{(5)} \mathrm{y}=223,3786+0,4658 \mathrm{x}-0,0032 \mathrm{x}^{2}\left(\mathrm{R}^{2}=0,80\right) ;{ }^{(6)} \mathrm{y}=84,4100-0,0623 \mathrm{x}\left(\mathrm{R}^{2}=0,86\right) ;{ }^{(7)} \mathrm{y}=79,3050-0,03223 \mathrm{x}+0,0013 \mathrm{x}^{2}\left(\mathrm{R}^{2}=0,82\right)$; ${ }^{(8)} \mathrm{y}=77,2414+0,0675 \mathrm{x}-0,0009 \mathrm{x}^{2}\left(\mathrm{R}^{2}=0,86\right)$. 
$\mathrm{O}$ aumento linear do número de colmos $\mathrm{m}^{-2} \mathrm{da}$ cultivar BRS Primavera também foi verificado por Gitti et al. (2011), em dois anos de avaliação com aplicações de subdoses de glyphosato. Estudos mais detalhados devem ser realizados para melhor clareza dos resultados.

O número de panículas $\mathrm{m}^{-2}$ da IAC 202 foi influenciado pelo aumento das doses do regulador de crescimento. Quanto ao perfilhamento útil, as cultivares BRS Primavera, IAC 202 e Caiapó apresentaram influência do aumento das doses do regulador (Tabela 2). Embora o número de colmos $\mathrm{m}^{-2}$ tenha sido incrementado até determinadas doses do regulador de crescimento, não houve aumento significativo do número de panículas $\mathrm{m}^{-2}$. Este fato refletiu negativamente no perfilhamento útil, tendo-se em vista o aumento de colmos inférteis.

Como já mencionado, o etil-trinexapac atua ao nível de metabolismo da síntese de giberelinas, hormônios que, dentre outras ações, promovem o alongamento celular. Neste caso específico, o regulador de crescimento pode ter influenciado na formação de perfilhos de ordens mais elevadas, como os terciários e quaternários, evitando a emissão de suas panículas, devido à redução do comprimento dos últimos internódios responsáveis pelo seu comprimento.

O número de grãos totais, cheios e chochos por panícula obtiveram diferenças significativas apenas para as cultivares. As doses do regulador de crescimento não influenciaram estas características (Tabela 3). A cultivar IAC 202 apresentou maior quantidade de grãos totais e cheios por panícula e menor quantidade de grãos chochos, em relação às demais cultivares. Resultado diferente foi obtido por Alvarez et al. (2007), que verificaram influência negativa nestes componentes da produção, com a aplicação do etil-trinexapac. Já Buzetti et al. (2006) verificaram que a aplicação do regulador de crescimento cloreto de clormequat influenciou o comprimento da panícula e o número de espiguetas por panícula. Para o número de espiguetas por panícula, os autores verificaram que, para as doses do regulador, houve ajuste à equação linear decrescente, no primeiro ano, e crescente, no segundo ano de cultivo, o que mostra a interação existente entre o regulador de crescimento e as condições climáticas, que podem variar de um ano para outro. Os autores ainda observaram que, no primeiro ano, as plantas apresentaram-se maiores e com melhor perfilhamento, maior índice de fertilidade e maior produtividade de grãos.
Para a massa de 100 grãos, massa hectolítrica e produtividade, verificou-se interação significativa dos dois fatores estudados (variedade $\mathrm{x}$ doses do regulador) (Tabela 4). Para a massa de 100 grãos, a cultivar Caiapó apresentou maiores valores, variando de 2,9 g a 3,2 g (Tabela 4). Esta cultivar apresenta grãos longos, enquanto, para as demais, estes são longos e finos (tipo agulhinha) e, por esta razão, a massa de 100 grãos é maior, em relação às cultivares BRS Primavera, BRS Soberana e IAC 202. Quanto às doses do regulador de crescimento, verificou-se que, para as cultivares BRS Primavera e Caiapó, as médias cresceram linearmente, com o aumento das doses de etil-trinexapac (Tabela 4).

Quanto à massa hectolítrica, verificou-se que, de maneira geral, a cultivar Caiapó apresentou os maiores valores (Tabela 4). A justificativa para este comportamento é a mesma apresentada para a massa de 100 grãos, ou seja, no caso das cultivares de grãos longos e finos (BRS Primavera, BRS Soberana e IAC 202), ocorre maior sobra de espaços entre os grãos, dentro do recipiente utilizado para avaliar a massa hectolítrica, resultando em valores menores. O aumento das doses do etil-trinexapac reduziram linearmente a massa hectolítrica da cultivar BRS Soberana. Nascimento et al. (2009) verificaram que, no caso das doses do regulador de crescimento etil-trinexapac, os valores obtidos para a massa hectolítrica se ajustaram à equação quadrática $y=52,6469+9,5815 x-5,2612 x^{2}$, de maneira

Tabela 3. Número de grãos totais, cheios e chochos por panícula, em função de doses de etil-trinexapac e cultivares de arroz de terras altas irrigadas por aspersão (Selvíria, MS, 2007/2008).

\begin{tabular}{lccc}
\hline Tratamentos & $\begin{array}{c}\text { Grãos } \\
\text { totais }\end{array}$ & $\begin{array}{c}\text { Grãos } \\
\text { cheios }\end{array}$ & $\begin{array}{c}\text { Grãos } \\
\text { chochos }\end{array}$ \\
\hline Cultivares & $163,4 \mathrm{~b}$ & $147,3 \mathrm{~b}$ & $16,2 \mathrm{~b}$ \\
BRS Primavera & $154,4 \mathrm{~b}$ & $131,1 \mathrm{c}$ & $23,4 \mathrm{a}$ \\
BRS Soberana & $195,1 \mathrm{a}$ & $181,6 \mathrm{a}$ & $13,6 \mathrm{c}$ \\
IAC 202 & $152,9 \mathrm{~b}$ & $140,5 \mathrm{bc}$ & $12,5 \mathrm{c}$ \\
Caiapó & $169,9^{\text {ns }}$ & $151,6^{\text {ns }}$ & $18,3^{\text {ns }}$ \\
Doses de etil-trinexapac $\left(\mathrm{g} \mathrm{ha^{-1 }}\right)$ & 151,7 & 14,3 \\
0 & 165,8 & 153,3 & 15,5 \\
50 & 168,9 & 149,4 & 16,8 \\
100 & 166,3 & 144,2 & 17,2 \\
150 & 161,4 & 13,485 & 2,507 \\
200 & 13,625 & 10,73 & 18,25 \\
\hline DMS (Cultivares) & 9,48 &
\end{tabular}

Médias seguidas de mesma letra minúscula, nas colunas, não diferem estatisticamente entre si, pelo teste Tukey, a $5 \%$. ${ }^{\text {ns }}$ Não significativo. 
Tabela 4. Massa de 100 grãos, massa hectolítrica e produtividade de grãos, em função de doses de etil-trinexapac e cultivares de arroz de terras altas irrigadas por aspersão (Selvíria, MS, 2007/2008).

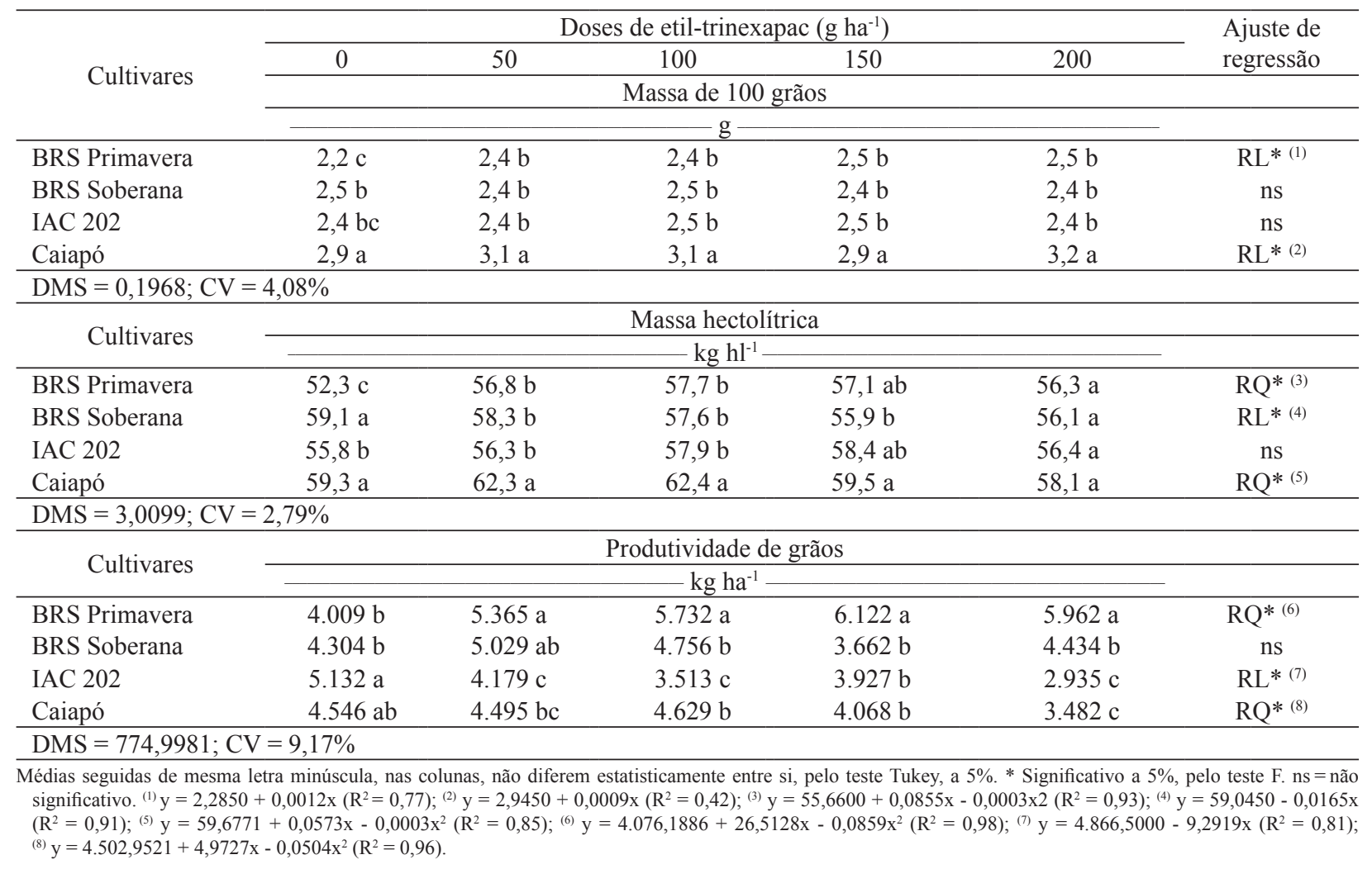

semelhante aos resultados obtidos para a cultivar BRS Primavera e Caiapó.

$\mathrm{Na}$ ausência do regulador de crescimento, houve destaque para a cultivar IAC 202, que apresentou maior produtividade $\left(5.132 \mathrm{~kg} \mathrm{ha}^{-1}\right)$, em relação à BRS Primavera e BRS Soberana, não diferindo da cultivar Caiapó (Tabela 4). Vale ressaltar que, mesmo sem regulador de crescimento, a cultivar IAC 202 não apresentou acamamento de plantas, portanto, pelos dados obtidos, não necessitaria da utilização de regulador vegetal.

Para os tratamentos com uso de regulador, houve, de maneira geral, destaque para a cultivar BRS Primavera, a qual apresentou maior produtividade $\left(6.122 \mathrm{~kg} \mathrm{ha}^{-1}\right)$, sendo a estimativa da dose obtida pela equação quadrática de $154 \mathrm{~g} \mathrm{ha}^{-1}$ do etil-trinexapac. Semelhantemente à cultivar BRS Primavera, a produtividade da cultivar Caiapó apresentou ajuste quadrático ao aumento das doses do regulador de crescimento, porém, com estimativa da dose e produtividade inferiores, ou seja, aproximadamente $50 \mathrm{~g} \mathrm{ha}^{-1}$ do etil-trinexapac e $4.626 \mathrm{~kg} \mathrm{ha}^{-1}$, respectivamente.
Para a cultivar IAC 202, os dados se ajustaram a uma função linear decrescente. Como já mencionado anteriormente, não há necessidade de uso do regulador, já que não houve acamamento de plantas, mesmo no tratamento testemunha. Nascimento et al. (2009) verificaram que a aplicação de $150 \mathrm{~g} \mathrm{ha}^{-1}$ de etil-trinexapac, no momento da diferenciação floral do arroz cultivar BRS Primavera, reduz a altura de plantas (na média em $0,40 \mathrm{~m}$, em relação às outras épocas avaliadas pelos autores), com ausência de acamamento, concordando com os resultados para a cultivar BRS Primavera obtidos no presente trabalho. Já Alvarez et al. (2007) observaram influência negativa na produtividade de grãos da cultivar BRS Primavera, obtendo resultados $25 \%$ inferiores, com a aplicação de $200 \mathrm{~g} \mathrm{ha}^{-1}$ do i.a., em relação à testemunha sem aplicação do regulador, sendo o experimento conduzido em vasos.

A influência do regulador de crescimento na produtividade de grãos foi semelhante entre as cultivares BRS Primavera e Caiapó e diferente da IAC 202. A cultivar BRS Primavera e Caiapó foram as únicas que obtiveram aumento na produtividade de grãos, com o aumento das doses do regulador até 
$150 \mathrm{~g} \mathrm{ha}^{-1}$ e $100 \mathrm{~g} \mathrm{ha}^{-1}$ de etil-trinexapac, respectivamente. Este benefício resultou dos incrementos lineares na massa de 100 grãos e eliminação de perdas de grãos, devido ao acamamento de plantas. A cultivar IAC 202 apresentou redução na produtividade de grãos, com o aumento das doses do regulador. A baixa estatura de planta da cultivar IAC 202 e a aplicação do regulador contribuiram para a retenção da panícula no colmo, devido à redução no pedúnculo da panícula, fato observado pelo decréscimo no número de panículas $\mathrm{m}^{-2}$, reduzindo, assim, a produtividade.

A utilização do regulador de crescimento cloreto de clormequat, nas doses $0 \mathrm{~L} \mathrm{ha}^{-1}, 1 \mathrm{~L} \mathrm{ha}^{-1} \mathrm{e}$ $2 \mathrm{~L} \mathrm{ha}^{-1}$, não alterou a altura e a produtividade das cultivares IAC 201 e IAC 202, em experimento a campo, segundo Buzetti et al. (2006). Vale ressaltar que os autores realizaram a aplicação do regulador cloreto de clormequat aos 20 e 30 dias após a emergência, na fase de perfilhamento, quando a distância entre os entrenós é pequena e não influencia, significativamente, na altura da planta. Aplicações tardias, como, por exemplo, na diferenciação floral do arroz, proporcionam reduções significativas nas plantas de arroz (Alvarez et al. 2007, Nascimento et al. 2009), uma vez que os 4 últimos entrenós determinam o tamanho da planta de arroz e são formados no início da diferenciação floral (Fornasieri Filho \& Fornasieri 2006).

\section{CONCLUSÕES}

1. A aplicação de $50 \mathrm{~g} \mathrm{ha}^{-1}, 100 \mathrm{~g} \mathrm{ha}^{-1}$ e $150 \mathrm{~g} \mathrm{ha}^{-1}$ de etil-trinexapac, por ocasião da diferenciação do primórdio da panícula das cultivares Caiapó, BRS Soberana e BRS Primavera, respectivamente, reduziu a altura de plantas e caracterizou-se pela ausência de acamamento.

2. A cultivar IAC 202 dispensou o uso de regulador de crescimento, considerando-se que a mesma não apresentou acamamento.

3. A aplicação de $50 \mathrm{~g} \mathrm{ha}^{-1}$ e $150 \mathrm{~g} \mathrm{ha}^{-1} \mathrm{de}$ etil-trinexapac, por ocasião da diferenciação do primórdio da panícula, aumentou a produtividade da cultivar Caiapó e BRS Primavera, respectivamente, e a dose de $100 \mathrm{~g} \mathrm{ha}^{-1}$ interferiu pouco na cultivar BRS Soberana.

\section{REFERÊNCIAS}

ALVAREZ, R. C. A. et al. Influência do etil-trinexapac no acúmulo, na distribuição de nitrogênio e na massa de grãos de arroz de terras altas. Revista Brasileira de Ciência do Solo, Viçosa, v. 31, n. 6, p. 1487-1496, 2007.

ARF, O. et al. Influência da época de semeadura no comportamento de cultivares de arroz irrigado por aspersão em Selvíria (MS). Pesquisa Agropecuária Brasileira, Brasília, DF, v. 35, n. 10, p. 1967-1976, 2000.

BASTOS, C. R. IAC 202: arroz de alta produtividade e qualidade para a cultura de sequeiro. O Agronômico, Campinas, v. 52, n. 1, p. 24-25, 2000.

BRESEGHELLO, F.; CASTRO, E. M.; MORAIS, O. P. Cultivares de arroz. In: BRESEGHELLO, F.; STONE, L. F. Tecnologia para arroz de terras altas. Santo Antônio de Goiás: Embrapa Arroz e Feijão, 1998. p. 41-53.

BUZETTI, S. et al. Resposta de cultivares de arroz a doses de nitrogênio e do regulador de crescimento cloreto de clormequat. Pesquisa Agropecuária Brasileira, Brasília, DF, v. 41, n. 12, p. 1731-1737, 2006.

CANTARELLA, H.; FURLANI, P. R. Arroz de sequeiro. In: RAIJ, B. V. et al. (Coords.). Recomendações de adubação e calagem para o Estado de São Paulo. 2. ed. Campinas: Instituto Agronômico, 1996. p. 48-49.

COMPANHIA NACIONAL DE ABASTECIMENTO (Conab). Acompanhamento da safra brasileira de grãos 2010/2011: $6^{\circ}$ levantamento, março de 2011. 2011. Disponível em: <www.conab.gov. br/.../11_03_10_09_03_02_boletim_marco-11\%5B1\%5D. pdf $>$. Acesso em: 25 mar. 2011.

COMPANHIA NACIONAL DE ABASTECIMENTO (Conab). Acompanhamento da safra brasileira de grãos 2011/2012: $7^{\circ}$ levantamento, abril de 2012. 2012. Disponível em: <www.conab.gov.br/OlalaCMS/uploads/ arquivos/12_03_13_11_04_08_boletim_marco_2012. pdf $>$. Acesso em: 24 abr. 2012.

EMPRESA BRASILEIRA DE PESQUISA AGROPECUÁRIA (Embrapa). Cultivares do arroz de terras altas no Estado de Mato Grosso. 2006. Disponível em: <www.cnpaf.embrapa.br/arroz/folderes/soberana. pdf $>$. Acesso em: 20 mar. 2011.

EMPRESA BRASILEIRA DE PESQUISA AGROPECUÁRIA (Embrapa). Sistema brasileiro de classificação de solos. Rio de Janeiro: Embrapa-CNPSO, 1999.

ESPINDULA, M. C. et al. Efeito de reguladores de crescimento na elongação do colmo de trigo. Acta Scientiarum Agronomy, Maringá, v. 32, n. 1, p. 109-116, 2010.

FORNASIERI FILHO, D.; FORNASIERI, J. L. Manual da cultura do arroz. Jaboticabal: Funep, 2006. 
GITTI, D. C. et al. Glyphosate como regulador de crescimento em arroz de terras altas. Pesquisa Agropecuária Tropical, Goiânia, v. 41, n. 4, p. 500-507, 2011.

HECKMAN, N. L. et al. Trinexapac-ethyl influence on cell membrane thermostability of Kenthucky bluegrass leaf tissue. Scientia Horticulturae, Amsterdam, v. 92, n. 2 , p. 183-186, 2002.

KAPPES, C. et al. Uso de reguladores de crescimento no desenvolvimento e produção de crotalária. Pesquisa Agropecuária Tropical, Goiânia, v. 41, n. 4, p. 508-518, 2011.

MATEUS, C. M. D. et al. Estratégias para redução do porte de girassol ornamental para comercialização em vaso. Bragantia, Campinas, v. 68, n. 3, p. 681-687, 2009.

MURATA, Y.; MATSUSHIMA, S. Rice. In: EVANS, L. T. (Ed.). Crop physiology. 4. ed. Cambridge: Cambridge University Press, 1978. p. 73-96.
NASCIMENTO, V. et al. Uso do regulador de crescimento etil-trinexapac em arroz de terras altas. Bragantia, Campinas, v. 68, n. 4, p. 921-929, 2009.

RADEMACHER, W. Growth retardants: effects on gibberellin biosynthesis and other metabolic pathways. Annual Review of Plant Physiology and Plant Molecular Biology, Palo Alto, v. 51, n. 1, p. 501-531, 2000.

RAIJ, B. V.; QUAGGIO, J. A. Métodos de análises de solo para fins de fertilidade. Campinas: IAC, 1983. (Boletim técnico, 81).

SOARES, A. A.; REIS, M. S.; SOARES, P. C. Caiapó, nova opção de arroz de sequeiro para Minas Gerais. Revista Ceres, Viçosa, v. 40, n. 231, p. 513-517, 1993.

ZAGONEL, J.; FERNANDES, E. C. Doses e épocas de aplicação do regulador de crescimento afetando cultivares de trigo em duas doses de nitrogênio. Planta Daninha, Viçosa, v. 25, n. 2, p. 331-339, 2007. 